\title{
Prognostic and predictive value of blood eosinophil count, fractional exhaled nitric oxide and their combination in severe asthma: a post-hoc analysis
}

\author{
Rahul Shrimanker \\ Oliver Keene* \\ Gareth Hynes \\ Sally Wenzel \\ Steven Yancey\# \\ Ian D Pavord
}

Oxford Respiratory NIHR Biomedical Research Centre, Nuffield Department of Medicine, NDM Research Building, University of Oxford, Old Road Campus, Oxford OX3 7FZ, UK. *Clinical Statistics, GlaxoSmithKline, Stockley Park, Middlesex, UK. The Department of Pulmonary, Allergy, and Critical Care Medicine, University of Pittsburgh Asthma Institute at the University of Pittsburgh Medical Center-University of Pittsburgh School of Medicine, Pittsburgh, USA. \#Respiratory Therapeutic Area. GlaxoSmithKline, Research Triangle Park, North Carolina, USA

Correspondence to lan D Pavord, Oxford Respiratory NIHR Biomedical Research Centre, Nuffield Department of Medicine, NDM Research Building, University of Oxford, Old Road Campus, Oxford OX3 7FZ

lan.pavord@ndm.ox.ac.uk 
To the editor,

Patients with severe eosinophilic asthma have a high risk of exacerbations requiring rescue oral corticosteroid treatment. Monoclonal antibody treatments inhibiting IL-5 directly or via the IL-5R $\alpha$ or IL13/IL4 via the IL-4R $\alpha$ reduce exacerbations of severe, eosinophilic asthma with evidence to type- 2 inflammation as shown by a raised peripheral blood eosinophil count or fractional exhaled nitric oxide (FeNO) (1) (2). Both of these biomarkers have been associated with an increased risk of exacerbations (3).

The key cytokine for the development of eosinophils is IL- 5 whereas FENO is regulated by the IL-13 dependant inducible nitric oxide pathway (4) suggesting that their combination might provide additive prognostic and predictive information. We tested this hypothesis in a post-hoc analysis of a placebo controlled trial of anti-IL-5 (mepolizumab) in patients with severe asthma.

\section{Methods}

We undertook a post-hoc analysis of a phase $2 \mathrm{~b}$ study of mepolizumab in patients with severe eosinophilic asthma (DREAM) (1). We selected this study as it was the only mepolizumab study to assess FeNO and blood eosinophils at baseline.

DREAM evaluated placebo and 3 doses of mepolizumab ( $75 \mathrm{mg}, 250 \mathrm{mg}, 750 \mathrm{mg}$ IV 4 weekly) for 52 weeks. Participants had a history of 2 or more exacerbations requiring oral corticosteroids in the previous year and evidence of eosinophilic inflammation as reflected by one of more of the following: a peripheral blood eosinophil count $\geq 300$ cells/ $\mu \mathrm{L}$; a sputum eosinophil count $\geq 3 \%$; FeNO $\geq 50 \mathrm{ppb}$; and prompt deterioration of asthma control after a $25 \%$ or less reduction in regular maintenance inhaled or oral corticosteroids. As the DREAM study did not show a dose-related effect of active treatment or evidence of an interaction between dose and predictive value of biomarkers, our analysis is based on the combined effect of the different doses. 
Participants were divided into subgroups depending on their baseline peripheral blood eosinophil count (PBE) and FeNO. PBE were defined as high ( $\geq 150$ cells $/ \mu \mathrm{L})$ or low ( $<150$ cells $/ \mu \mathrm{L})$ and FeNO as high ( $\geq 25 \mathrm{ppb})$ or low $(<25 \mathrm{ppb})$. We chose these cut points because of pre-existing evidence linking them to eosinophilic airway inflammation and response to corticosteroids(5). Baseline demographics, clinical characteristics and annualised exacerbation rates were calculated based on 4 biomarker subgroups; PBE high-FeNO high, PBE high-FENO low, PBE low-FENO high, PBE low-FeNO low. An additional analysis was carried out using a PBE cutpoint of 300 cells $/ \mu \mathrm{L}$.

The DREAM study was a multi-centre, randomised, double blind, placebo-controlled trial. Our primary interest was severe exacerbation rate, defined as the requirement for rescue oral corticosteroids, as the main benefit of mepolizumab treatment is to reduce the rate of exacerbations and exacerbation rate was the primary outcome measure of the trial. We also present the change in pre-bronchodilator $\mathrm{FEV}_{1}$ after 52 weeks of treatment.

\section{Results}

606 DREAM participants had baseline blood eosinophil and FeNO measurements. The study population had a mean of 3.6 exacerbations per patient per year in the year prior to study enrolment. Lung function was reduced, with a mean FEV1 of $60 \%$ predicted and there was a high symptom burden with a mean ACQ6 score of 2.3 ( $<1.5$ indicating good control). The baseline demographics and clinical characteristics of the study patients across biomarker subgroups and treatment are shown in table 1. 
Please insert table here. 
The risk of exacerbations was highest in placebo treated patients with high baseline PBE and FeNO. The efficacy of active treatment was most marked in this group with mepolizumab showing $61 \%$ exacerbation rate reduction, compared to $33 \%$ exacerbation rate reductions in the PBE high-FeNO group. Mepolizumab did not have a significant effect on exacerbation rate in the PBE low subgroups

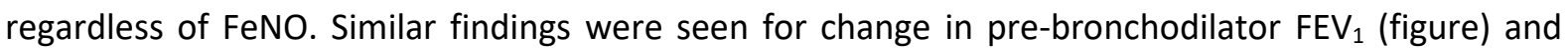
when patients were stratified by a PBE of 300 cells/ $\mu \mathrm{L}$ (online figure).

\section{Discussion}

We found that in patients with severe asthma treated with placebo who had high blood eosinophil counts and FeNO the rate of severe exacerbations requiring oral corticosteroid treatment was up to twice that seen in placebo treated patients with low or discordant biomarker results. The different biomarker groups had similar baseline lung function, symptom scores and exacerbation risk indicating that the increased risk of exacerbation events is independent of these other markers of asthma control and risk indicating that biomarker profiling of patients with severe asthma adds predictive value to a traditional risk assessment.

To evaluate the relationship between biomarker profile and treatment efficacy, we compared our findings with published results of the phase 3 trial of monoclonal antibody dupilumab (QUEST), a monoclonal antibody that blocks IL-13 and IL-4 by binding to the IL-4 receptor- $\alpha$ (2). This study evaluated 2 doses of dupilumab (200mg or $300 \mathrm{mg}$ SC 2 weekly) for 52 weeks in 1902 patients with moderate-severe persistent, uncontrolled asthma as per the GINA guidelines (6). Both doses had equivalent efficacy and, as combined data is not available, we present data from the 934 patients randomised to dupilumab $200 \mathrm{mg}$ every two weeks or matched placebo. Information on change in pre-bronchodilator $\mathrm{FEV}_{1}$ by biomarker profile was not available for QUEST (figure). The efficacy of dupilumab on exacerbations was most marked in the PBE high-FENO high group with a $68 \%$ reduction. There was also an exacerbation rate reduction of 33\% in the PBE high-FeNO low group 
which was similar to the effect seen in this subgroup with mepolizumab treatment. In the PBE lowFeNO low group neither biologic had a significant effect on exacerbations. In the PBE low-FeNO high group a $39 \%$ exacerbation rate reduction was seen with dupilumab. Athough not statistically significant, this finding contrasts to the absence of effect seen with mepolizumab in this subgroup.

The study populations differed significantly with the DREAM population having a higher exacerbation risk and a higher proportion of patients using high dose inhaled or regular oral corticosteroids. However, the higher risk of exacerbation in patients with higher blood eosinophils and FeNO was seen in both populations suggesting a true effect seen across a range of asthma severity. This is in keeping with earlier studies showing that a composite profile of biomarkers of type-2 airway inflammation provides prognostic information over and above a assessment of risk of exacerbation based on traditional asthma measures although this earlier study used a composite score of blood eosinophils, serum periostin and FeNO biomarkers (7). We extend these earlier findings by showing that patients with both high blood eosinophil counts and FeNO also had the greatest response to biological treatment with mepolizumab and dupilumab, indicating that biomarker profiles have predictive as well as prognostic value.

These greater prognostic value of the combined biomarker profile make biological sense given the biomarkers relate to different aspects of type- 2 immune responses in the airway. The peripheral blood eosinophil count reflects airway and systemic IL-5 production and is reduced markedly by antiIL-5 (1) but not dupilumab (2). In contrast, FeNO reflects airway IL-13 activity as it is reduced markedly by anti-IL-13 and dupilumab (2) but not anti-IL-5 (1). Thus, the two measures provide a more complete assessment of type- 2 immune responses in the airway. It is also likely that the combination of a systemic and local airway measure adds precision to an assessment in only one of these compartments. We did not find a point estimate improvement for mepolizumab in patients 
with high FeNO but low PBE as might be expected as FeNO is a marker of IL-13 activity in the airway. In contrast, there was a trend for benefit of dupilumab in this group.

Caution is required in interpreting this post-hoc subgroup analysis since the number of patients in some subgroups is small and the populations studied in DREAM and QUEST were different. We acknowledge that the relative efficacy of mepolizumab and dupilumab treatment in subgroups may reflect the play of chance or differences in patient populations as well as the different cytokine associations of the biomarkers. However, it is striking that the relative exacerbation rate reductions in three of the four subgroups were very similar. Our findings suggest that biomarker profiles might have value in identifying patients suitable for different biological agents. Formal head-to-head studies in similar patient populations are needed to assess this possibility prospectively. Future studies should also model the relationship between biomarker values and exacerbations more completely, allowing more accurate inferences to be drawn on individual patient responses. 


\section{Legend to figure}

Annualised exacerbation rates and improvement in pre-bronchodilator $\mathrm{FEV}_{1}$ with 52 weeks treatment with mepolizumab or placebo. Equivalent exacerbation rates for Dupilumab $200 \mathrm{mg}$ every 2 weeks and placebo are shown for comparison.

\section{Legend to on-line supplement figure}

Annualised exacerbation rates and improvement in pre-bronchodilator $\mathrm{FEV}_{1}$ with 52 weeks treatment with mepolizumab or placebo with a peripheral blood eosinophil cutpoint of $300 \mathrm{cells} / \mu \mathrm{L}$ 


\section{Reference List}

1. Pavord ID, Korn S, Howarth P, Bleecker ER, Buhl R, Keene ON, Ortega H, Chanez P. Mepolizumab for severe eosinophilic asthma (DREAM): a multicentre, double-blind, placebo-controlled trial. Lancet 2012; 380: 651-659.

2. Castro M, Corren J, Pavord ID, Maspero J, Wenzel S, Rabe KF, Busse WW, Ford L, Sher L, FitzGerald JM, Katelaris C, Tohda Y, Zhang B, Staudinger H, Pirozzi G, Amin N, Ruddy M, Akinlade B, Khan A, Chao J, Martincova R, Graham NMH, Hamilton JD, Swanson BN, Stahl N, Yancopoulos GD, Teper A. Dupilumab Efficacy and Safety in Moderate-to-Severe Uncontrolled Asthma. N Engl J Med 2018; 378: 2486-2496.

3. Malinovschi A, Fonseca JA, Jacinto T, Alving K, Janson C. Exhaled nitric oxide levels and blood eosinophil counts independently associate with wheeze and asthma events in National Health and Nutrition Examination Survey subjects. The Journal of allergy and clinical immunology 2013; 132: 821-827.e821-825.

4. Arron JR, Choy DF, Scheerens H, Matthews JG. Noninvasive biomarkers that predict treatment benefit from biologic therapies in asthma. Ann Am Thorac Soc 2013; 10 Suppl: S206-213.

5. Pavord ID, Afzalnia S, Menzies-Gow A, Heaney LG. The current and future role of biomarkers in type 2 cytokine-mediated asthma management. Clin Exp Allergy 2017; 47: 148-160.

6. Global Initiative for Asthma. Global Strategy for Asthma Management and Prevention. www.ginasthma.org. 2016 [cited 2016 11th May].

7. Heaney LG, Djukanovic R, Woodcock A, Walker S, Matthews JG, Pavord ID, Bradding P, Niven R, Brightling CE, Chaudhuri R, Arron JR, Choy DF, Cowan D, Mansur A, Menzies-Gow A, Adcock I, Chung KF, Corrigan C, Coyle P, Harrison T, Johnston S, Howarth P, Lordan J, Sabroe I, Bigler J, Smith D, Catley M, May R, Pierre L, Stevenson C, Crater G, Keane F, Costello RW, Hudson V, Supple D, Hardman T. Research in progress: Medical Research Council United Kingdom Refractory Asthma Stratification Programme (RASP-UK). Thorax 2016; 71: 187-189. 
Table. Baseline demographics and disease characteristics of DREAM patients divided by baseline PBE and FeNO subgroup and randomised treatment.

\begin{tabular}{|c|c|c|c|c|c|c|c|c|c|c|}
\hline & \multicolumn{2}{|c|}{$\begin{array}{l}\mathrm{PBE}<150 \text { cells } / \mu \mathrm{L}, \\
\mathrm{FeNO}<25 \mathrm{ppb}\end{array}$} & \multicolumn{2}{|c|}{$\begin{array}{c}\mathrm{PBE}<150 \text { cells } / \mu \mathrm{L}, \\
\mathrm{FeNO} \geq 25 \mathrm{ppb}\end{array}$} & \multicolumn{2}{|c|}{$\begin{array}{l}\mathrm{PBE} \geq 150 \text { cells } / \mu \mathrm{L}, \\
\mathrm{FeNO}<25 \mathrm{ppb}\end{array}$} & \multicolumn{2}{|c|}{$\begin{array}{l}\text { PBE } \geq 150 \text { cells } / \mu \mathrm{L}, \\
\mathrm{FeNO} \geq 25 \mathrm{ppb}\end{array}$} & \multicolumn{2}{|c|}{ Total } \\
\hline & $\begin{array}{l}\text { Placebo } \\
(\mathrm{N}=18)\end{array}$ & $\begin{array}{c}\text { Mepolizumab } \\
(\mathrm{N}=57)\end{array}$ & $\begin{array}{l}\text { Placebo } \\
(\mathrm{N}=14)\end{array}$ & $\begin{array}{c}\text { Mepolizumab } \\
(\mathrm{N}=57)\end{array}$ & $\begin{array}{l}\text { Placebo } \\
(\mathrm{N}=35)\end{array}$ & $\begin{array}{c}\text { Mepolizumab } \\
(\mathrm{N}=127)\end{array}$ & $\begin{array}{c}\text { Placebo } \\
(\mathrm{N}=84)\end{array}$ & $\begin{array}{c}\text { Mepolizumab } \\
(\mathrm{N}=214)\end{array}$ & $\begin{array}{l}\text { Placebo } \\
(\mathrm{N}=151)\end{array}$ & $\begin{array}{c}\text { Mepolizumab } \\
(\mathrm{N}=455)\end{array}$ \\
\hline Age, years, mean (SD) & $44.3(12.07)$ & $52.7(11.79)$ & $45.5(10.55)$ & $50.6(8.27)$ & 45.9 (11.05) & $48.0(10.99)$ & 46.9 (11.54) & $49.2(11.49)$ & $46.2(11.33)$ & $49.5(11.10)$ \\
\hline Female, n (\%) & $11(61)$ & $38(67)$ & $7(50)$ & $34(60)$ & $29(83)$ & $83(65)$ & $49(58)$ & $132(62)$ & $96(64)$ & $287(63)$ \\
\hline ICS Dose $(\mu \mathrm{g} / \text { day })^{1}$, mean (SD) & $1053(356)$ & $1108(434)$ & $1033(115)$ & $1077(567)$ & $1175(464)$ & $1150(523)$ & $1169(608)$ & $1094(447)$ & $1145(523)$ & $1109(483)$ \\
\hline Maintenance OCS use, $n$ (\%) & $2(11)$ & $18(32)$ & $5(36)$ & $22(39)$ & $8(23)$ & $25(20)$ & $27(32)$ & $75(35)$ & $42(28)$ & $140(31)$ \\
\hline $\begin{array}{l}\text { Pre-bronchodilator FEV1, mL, } \\
\text { mean (SD) }\end{array}$ & $2253(812.2)$ & $1747(631.1)$ & 2105 (811.7) & $1888(647.0)$ & $1611(506.3)$ & $1845(636.2)$ & $1919(605.8)$ & $1911(678.8)$ & 1905 (656.9) & $1869(657.4)$ \\
\hline $\begin{array}{l}\text { Pre-bronchodilator \%predicted } \\
\text { FEV1, mean (SD) }\end{array}$ & $66.3(17.05)$ & $59.2(14.99)$ & $58.2(12.90)$ & $60.6(15.22)$ & $53.9(12.77)$ & $59.3(16.57)$ & $60.5(15.54)$ & $60.3(16.24)$ & $59.4(15.21)$ & $59.9(16.01)$ \\
\hline $\begin{array}{l}\text { Post-bronchodilator FEV1, mL, } \\
\text { mean (SD) }\end{array}$ & $2688(821.8)$ & $2008(706.1)$ & $2648(948.3)$ & $2178(725.5)$ & $1927(652.8)$ & $2154(680.0)$ & $2311(725.0)$ & $2297(764.4)$ & 2298 (777.1) & $2206(733.8)$ \\
\hline ACQ-6 Score, mean (SD) & $2.6(1.20)$ & $2.1(1.02)$ & $2.5(0.82)$ & $2.5(0.98)$ & $2.4(1.11)$ & $2.1(1.13)$ & $2.5(1.08)$ & $2.4(1.11)$ & $2.5(1.07)$ & $2.3(1.10)$ \\
\hline 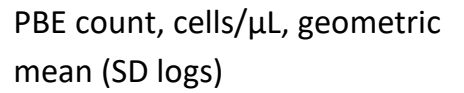 & $80(0.57)$ & $50(0.95)$ & $50(0.89)$ & $80(0.72)$ & $350(0.66)$ & $350(0.54)$ & $450(0.61)$ & $410(0.63)$ & $280(1.01)$ & $240(1.03)$ \\
\hline $\begin{array}{l}\text { FeNO count, ppb, geometric } \\
\text { mean (SD logs) }\end{array}$ & $14.6(0.39)$ & $12.3(0.45)$ & $42.3(0.49)$ & $54.0(0.47)$ & $14.4(0.34)$ & $15.2(0.42)$ & $55.5(0.55)$ & $51.2(0.50)$ & $33.7(0.79)$ & $30.7(0.79)$ \\
\hline $\begin{array}{l}\text { Exacerbations in year prior to } \\
\text { study, mean (SD) }\end{array}$ & $2.7(1.87)$ & $3.3(2.50)$ & $3.5(1.99)$ & $3.9(3.06)$ & $2.9(1.09)$ & $3.0(2.03)$ & $4.4(4.87)$ & $3.8(3.16)$ & $3.8(3.83)$ & $3.5(2.81)$ \\
\hline Requiring hospitalization, $\mathrm{n}(\%)$ & $4(22)$ & $20(35)$ & $3(21)$ & $17(30)$ & $7(20)$ & $28(22)$ & $25(30)$ & $44(21)$ & $39(26)$ & $109(24)$ \\
\hline
\end{tabular}

1. ICS doses are presented as ex-valve/metered doses and are based on conversions to an FP equivalent dose.

ACQ, asthma control questionnaire; FeNO, fractional exhaled nitric oxide; FEV1, forced expiratory volume in 1 second; ICS, inhaled corticosteroids; OCS, oral corticosteroids;

PBE, peripheral blood eosinophil count; ppb, parts per billion; SD, standard deviation. 